\section{Análise comparativa da base social da Medicina e Enfermagem no Brasil entre os anos de 2000 e 2010}

\author{
Comparative analysis of the social base of the \\ medical and nursing professions in Brazil from \\ 2000 to 2010
}
Análisis comparativo sobre la base social en Medicina y enfermería en Brasil entre los años 2000 y 2010

Lucas Wan Der Maas 1,2

doi: 10.1590/0102-311X00199116

\section{Resumo}

O objetivo deste artigo é analisar as alterações ocorridas durante os anos 2000 na base social das profissões da Medicina e Enfermagem no Brasil, como resultado da expansão do Ensino Superior iniciada na segunda metade dos anos 1990. De um lado, analisa descritivamente a base social de recrutamento valendo-se dos dados do questionário socioeconômico do Exame Nacional de Desempenho dos Estudantes de 2004 e 2010, referentes aos ingressantes e concluintes dos cursos de Medicina e Enfermagem. De outro, analisa a base social dos habilitados nas profissões valendo-se dos dados do Censo Demográfico do Instituto Brasileiro de Geografia e Estatística de 2000 e 2010. Os resultados mostram que ocorreu ampliação da base social de recrutamento das duas profissões, sobretudo pelo crescimento do alunado proveniente de famílias de baixa renda e que se declararam negros/as, pardos/as e mulato/as. Já a base social dos habilitados passou por uma reconfiguração, caracterizada pelo rejuvenescimento da população e pela diminuição das recompensas no mercado de trabalho. Ambos os processos foram vivenciados de forma distinta entre e dentro das profissões, destacando a existência de diferenças na capacidade de cada grupo profissional em mobilizar recursos que são próprios do mundo profissional e que lhes podem garantir posições especiais no mercado de trabalho e na estrutura social.

Ocupações em Saúde; Ocupações Relacionadas com Saúde;

Educação Superior; Medicina; Enfermagem

\author{
Correspondência \\ L. Wan Der Maas \\ Universidade Federal de Minas Gerais. \\ Av. Alfredo Balena 190, sala 721, Belo Horizonte, \\ MG 30130-100, Brasil. \\ lucaswander@hotmail.com \\ 1 Universidade Federal de Minas Gerais, Belo Horizonte, Brasil. \\ 2 Pontifícia Universidade Católica de Minas Gerais, \\ Belo Horizonte, Brasil.
}


$\mathrm{O}$ artigo tem por objetivo descrever quem são os membros que compõem os grupos profissionais dos médicos e enfermeiros no Brasil. Mais especificamente qual é a base social das duas profissões e como ela se modificou no período expansionista do Ensino Superior do país ocorrido nos anos 2000. Entende-se por base social da profissão o conjunto de indivíduos com probabilidade de fazer parte do grupo profissional, considerando aqueles em fase de recrutamento (estudantes dos cursos de graduação que se habilitam para o exercício da profissão) e os já habilitados (portadores de diploma), com os seus atributos definidores em torno de marcadores sociais, tais como sexo, raça, idade, classe social, posição familiar, posição no mercado de trabalho, rendimentos, entre outros.

A escolha pelas profissões da Medicina e Enfermagem é justificada pelas situações quase opostas que elas representam em termos de base social, bem como pela forma diferenciada como cada profissão experimentou as transformações ocorridas na sociedade brasileira no período em questão. Embora outras profissões pudessem ser escolhidas, espera-se um efeito explicativo interessante ao comparar profissões que na divisão do trabalho se relacionam de forma direta e hierárquica, ainda que ambas tenham o mesmo nível de escolaridade exigido ao exercício. Assim, a comparação tem por objetivo explicar as formas distintas e, em grande medida, desiguais, de inserção no mercado de trabalho e, consequentemente, de obtenção de recompensas derivadas da posse de um diploma universitário.

Muitas são as razões que explicam as diferenças entre indivíduos diplomados, isto é, entre profissionais. A explicação que embasa o argumento deste artigo se sustenta na Sociologia das Profissões. Embora composta de diferentes paradigmas, de maneira geral, na Sociologia, as profissões se destacam como categorias sociais privilegiadas quanto ao acesso a posições sociais elevadas na estrutura social. Isso ocorre pela conquista dos chamados "espaços sociais profissionalizados" por meio de um processo de diferenciação e luta por status, em que grupos ocupacionais específicos passam a exercer o controle de determinadas áreas da divisão do trabalho e da vida social. Diz-se que as profissões utilizam recursos específicos (tais como treinamento universitário, controle corporativo e monopólio do exercício concedido pelo Estado) para se diferenciar de outras ocupações e, assim, alcançar níveis superiores na estrutura social 1,2,3,4.

Entretanto, as posições sociais que ocupam não são homogêneas, tendo em vista a existência de diferenças e hierarquias entre grupos profissionais e no interior de um mesmo grupo. Mesmo que os profissionais possam ser identificados em mais de um estrato da estrutura social e embora eles também possam ser entendidos como membros de grupos sociais fechados, a observação de fatores individuais, de mercado de trabalho, de organização do sistema escolar e de valores atribuídos aos conteúdos do saber que representam revela padrões que variam por profissão. Esses são efeitos da reprodução das desigualdades que são próprios do profissionalismo, afinal, existem profissões com mais prestígio e que produzem vantagens econômicas e simbólicas mais expressivas, e existem distinções entre indivíduos de uma mesma profissão que são geradas por oportunidades variadas que estes adquirem ao longo da vida 1,5,6.

As profissões atuam socialmente, em maior ou menor grau, a partir do prestígio e autoridade social que têm. O capital cultural controlado por elas é fundamental nos processos de produção e reprodução das desigualdades. O tipo de conhecimento (se mais abstrato ou mais técnico) e a forma de controlá-lo definem em grande medida os valores distintos dos títulos acadêmicos, afinal estes são as bases da identidade e do poder dos grupos profissionais. Embora possam ser atribuídas diferenças em termos da complexidade do saber que representam, tais diferenças são socialmente atribuídas e, portanto, revelam senão uma forma de distinção social que por si só também é explicativa das diferenças observadas na posição social de seus membros 2 .

A análise do presente artigo foi realizada em dois momentos distintos. Inicialmente, apresenta-se descritivamente a base social de recrutamento das duas profissões, com dados socioeconômicos sobre os estudantes ingressantes e concluintes dos cursos de Medicina e Enfermagem nos anos 2004 e 2010. Em seguida, ainda de forma descritiva, apresenta-se a base social dos habilitados nas profissões por meio de dados demográficos e de inserção laboral dos médicos e enfermeiros nos anos 2000 e 2010. De forma preliminar e descritiva, pretende-se contribuir para o debate sobre os efeitos da expansão do Ensino Superior assistida no período para o uso dos títulos universitários como meio de organizar hierarquias sociais na sociedade brasileira. Em outras palavras, busca-se explicar em que medida os percursos da Medicina e da Enfermagem ao longo do processo de expansão do Ensino Superior dos anos 2000 refletem as desigualdades presentes no mundo profissional. 


\section{Metodologia}

Para análise da base social de recrutamento de médicos e enfermeiros e suas alterações ao longo dos anos 2000 utilizaram-se os dados do questionário socioeconômico (QSE) do Exame Nacional de Desempenho dos Estudantes (ENADE), do Ministério da Educação, dos anos de 2004 e 2010 (Instituto Nacional de Estudos e Pesquisas Educacionais Anísio Teixeira - INEP. http://portal.inep.gov. br/basica-levantamentos-acessar, acessado em 03/Out/2016). O exame tem por objetivo avaliar o desempenho dos estudantes de graduação e um dos seus componentes é o QSE, respondido pelos próprios estudantes no momento da avaliação. Nos anos em questão, foram aplicados a uma amostra de ingressantes e concluintes dos cursos de graduação da área da saúde, convocada compulsoriamente. A grande maioria compareceu ao exame e, destes, outra maioria respondeu ao QSE. A amostra utilizada neste artigo é constituída, portanto, desse último grupo, distribuído da seguinte forma: (i) estudantes de Medicina - 7.885 em 2004 (sendo 4.503 ingressantes e 3.382 concluintes) e 24.424 em 2010 (15.022 ingressantes e 9.402 concluintes); (ii) estudantes de Enfermagem - 19.496 em 2004 (13.474 ingressantes e 6.022 concluintes) e 55.754 em 2010 (30.084 ingressantes e 25.670 concluintes).

As variáveis usadas foram: grau de escolaridade do pai e da mãe (nenhuma escolaridade, Ensino Fundamental de 1ạ a 4ạ série, Ensino Fundamental de 5ạ a $8 \underline{a}$ série, Ensino Médio, Ensino Superior); renda familiar (até 3 salários mínimos, mais de 3 até 10, mais de 10 até 30, mais de 30); tipo de escola onde cursou o Ensino Médio (todo em escola pública, todo em escola privada, a maior parte em pública, a maior parte em privada, e metade em escola pública e metade em privada); se trabalhou durante o curso (nunca trabalhou, trabalha/ou eventualmente, trabalha/ou menos de 40 horas semanais e trabalha/ou 40 horas ou mais); e se recebe ou recebeu bolsa de estudo ou financiamento. Também foram incluídas as variáveis de sexo, faixa etária, estado civil, raça (branca, negra/parda/mulata, amarela e indígena) e com quem mora atualmente (sozinho(a), com os pais/parentes, com cônjuge e/ou filho(s), com amigos ou em alojamento). Por fim, as variáveis de natureza jurídica (pública ou privada) e forma de organização (universidade, centro universitário ou faculdade) da Instituição de Ensino Superior (IES). As categorias de algumas variáveis foram modificadas de maneira a compatibilizar as diferentes versões do questionário em 2004 e 2010.

Para análise da base social dos habilitados nas profissões utilizaram-se os dados da amostra do Censo Demográfico do Instituto Brasileiro de Geografia e Estatística (IBGE) de 20007 e de 2010 (http:// ftp.ibge.gov.br/Censos/Censo_Demografico_2010/Resultados_Gerais_da_Amostra/Microdados/, acessado em 27/Abr/2012). O censo permite atribuir aos entrevistados uma profissão de nível superior derivada do último curso de graduação concluído, quando o maior nível de formação é a graduação. Para indivíduos com formação em pós-graduação ou que realizaram outro curso de graduação após aquele específico da profissão, a identificação do mesmo só pode ser feita pela ocupação no trabalho principal. Por exemplo, um médico que concluiu um curso de Direito após o de Medicina ou que fez um mestrado, não tem registro do curso de Medicina na variável que identifica a graduação. Assim, sua identificação só foi possível caso estivesse ocupado como "médico" no trabalho principal. Em todos os casos que o entrevistado tenha sido identificado em mais de uma profissão, seja pelo critério educacional seja pelo ocupacional, utilizou-se a ocupação como critério final de enquadramento. Além desses critérios, foram excluídos casos inconsistentes quanto à idade e escolaridade informadas. Portanto, foram selecionados todos os entrevistados com graduação em Medicina e Enfermagem e/ ou que estavam ocupados como médicos e enfermeiros, perfazendo as seguintes amostras: 24.159 médicos e 8.838 enfermeiros, em 2000; 23.936 e 29.207, em 2010, respectivamente.

As variáveis elencadas para análise da composição foram: sexo, faixa etária, raça/cor da pele (branca, preta, parda, amarela e indígena), posição domiciliar (responsável pelo domicílio, cônjuge ou companheiro(a), filho(a) ou enteado(a), outro parente e outra posição) e condição de atividade (ocupado na profissão, ocupado em outra profissão de nível superior, ocupado em ocupação que não exige nível superior, desocupado, e não economicamente ativo). Adicionalmente, para a população de profissionais ocupados na própria profissão foram analisadas as variáveis referentes ao trabalho principal da semana de referência: posição na ocupação (celetista, estatutário, conta própria, empregador e não remunerado), carga horária semanal, se contribuía para a Previdência, se estava aposentado, decis do rendimento mensal do trabalho e decis do rendimento domiciliar per capita (considerando-se as distribuições de renda do total da população ocupada no país e do total dos domicílios, respectivamente). 
Os resultados encontrados para as profissões em questão foram comparados em relação ao total da população com nível superior.

Além da análise da base social, foram estimados inicialmente os quantitativos de médicos e enfermeiros ao longo de uma série histórica mais ampliada, considerando-se os períodos anteriores e posteriores aos anos de 2000 e 2010. Assim, foram identificados: (i) o número de profissionais em 1991 usando-se o Censo Demográfico correspondente 8; (ii) o acumulado de novos profissionais entre $1991 \mathrm{e}$ 2014 por meio do Censo da Educação Superior do INEP (http://portal.inep.gov.br/censo-da-educacaosuperior); (iii) o número de profissionais com registro ativo no Conselho Federal de Medicina (CFM; http://portal.cfm.org.br/index.php?option=com_estatistica, acessado em 24/Mai/2017) e no Conselho Federal de Enfermagem (Cofen; http://www.cofen.gov.br/enfermagem-em-numeros, acessado em 24/Mai/2017) em 2017.

Os dados foram obtidos por meio de download público disponível nos sites do INEP e do IBGE ou pela obtenção de CD-ROM, no caso dos Censos Demográficos de 2000 e 1991. O tratamento e análise estatística descritiva das variáveis foram realizados no software SPSS (SPSS Inc., Chicago, Estados Unidos). Em função da robustez das amostras, em termos de tamanho e nível de confiança, não foi necessário aplicar testes para verificar se as diferenças observadas entre as subamostras (Medicina e Enfermagem) são estatisticamente significantes. A presente análise faz parte de uma pesquisa mais ampla, a qual foi submetida ao Comitê de Ética da Pontifícia Universidade Católica de Minas Gerais (CAAE: 56557316.5.0000.5137). Ressalta-se, porém, que os dados utilizados são públicos e em formato agregado, não permitindo a identificação dos sujeitos.

\section{Resultados}

No período compreendido entre 1991 e 2010, observou-se que o número de médicos no país passou de 182.358 para 338.454, sendo que o acumulado de novos profissionais no período chegou a 171.812 Já a Enfermagem cresceu de forma ainda mais expressiva, variando de 53.340 a 338.717 profissionais, com um acumulado de 287.275 egressos. Note-se que a população de médicos cresceu 3,6\% ao ano e a de enfermeiros 14,8\% ao ano. Em 2014, o acumulado de novos profissionais chegou a $235.405 \mathrm{em}$ Medicina e a 444.596 em Enfermagem. Em 2017, o Conselho Federal de Medicina registrou 438.085 médicos ativos. No mesmo ano, o Conselho Federal de Enfermagem registrou 467.782 enfermeiros ativos (Figura 1).

\section{Base social de recrutamento das profissões}

As Tabelas 1 e 2 apresentam o perfil demográfico e socioeconômico dos estudantes ingressantes e concluintes dos cursos de Medicina e Enfermagem no Brasil nos anos de 2004 e 2010, segundo os dados do questionário socioeconômico do ENADE. Pode-se afirmar que ocorreu uma ampliação da base social de recrutamento das duas profissões. Considerando-se que a mesma foi ascendente nos fluxos de entrada e de saída dos cursos ao longo da década de 2000, verifica-se uma tendência consistente de ampliação. Essa ascendência aconteceu principalmente pelo crescimento do acesso e da permanência do alunado proveniente de famílias nas faixas de renda mais baixas, que recebiam ou receberam bolsa ou financiamento, que cursaram todo o ensino médio em escola pública e que se declaravam negros(as), pardos(as) ou mulatos(as).

No caso específico da Medicina, ocorreu aumento da participação feminina, de 52,2\% para $55,7 \%$, entre ingressantes, e de $48,3 \%$ para $54,7 \%$, entre concluintes (Tabela 1). Em relação à idade, a faixa etária de até 24 anos diminuiu, cedendo espaço para a faixa seguinte, de 25 a 29 anos. A proporção de negros(as), pardos(as) e mulatos(as) passou de $17,7 \%$ para 25,6\% e de 15,5\% para 23\%, respectivamente, entre ingressantes e concluintes, sendo que diminuíram as proporções de brancos(as) e amarelos(as). No que se refere à conjugalidade, os dados mostram uma diferença significativa quando se comparam os alunos que estavam no início dos cursos com os do final. As proporções de casados e dos que moravam com cônjuge e/ou filho(s) eram maiores nesse último grupo. Os que moravam com os pais/parentes também eram mais representativos entre os concluintes, e os que moravam sozinhos(as) ou com amigos ou em alojamento, entre os ingressantes. Não se observaram 


\section{Figura 1}

Evolução do número de médicos e enfermeiros residentes no país e acumulado de novos profissionais. Brasil, 1991 a 2017.

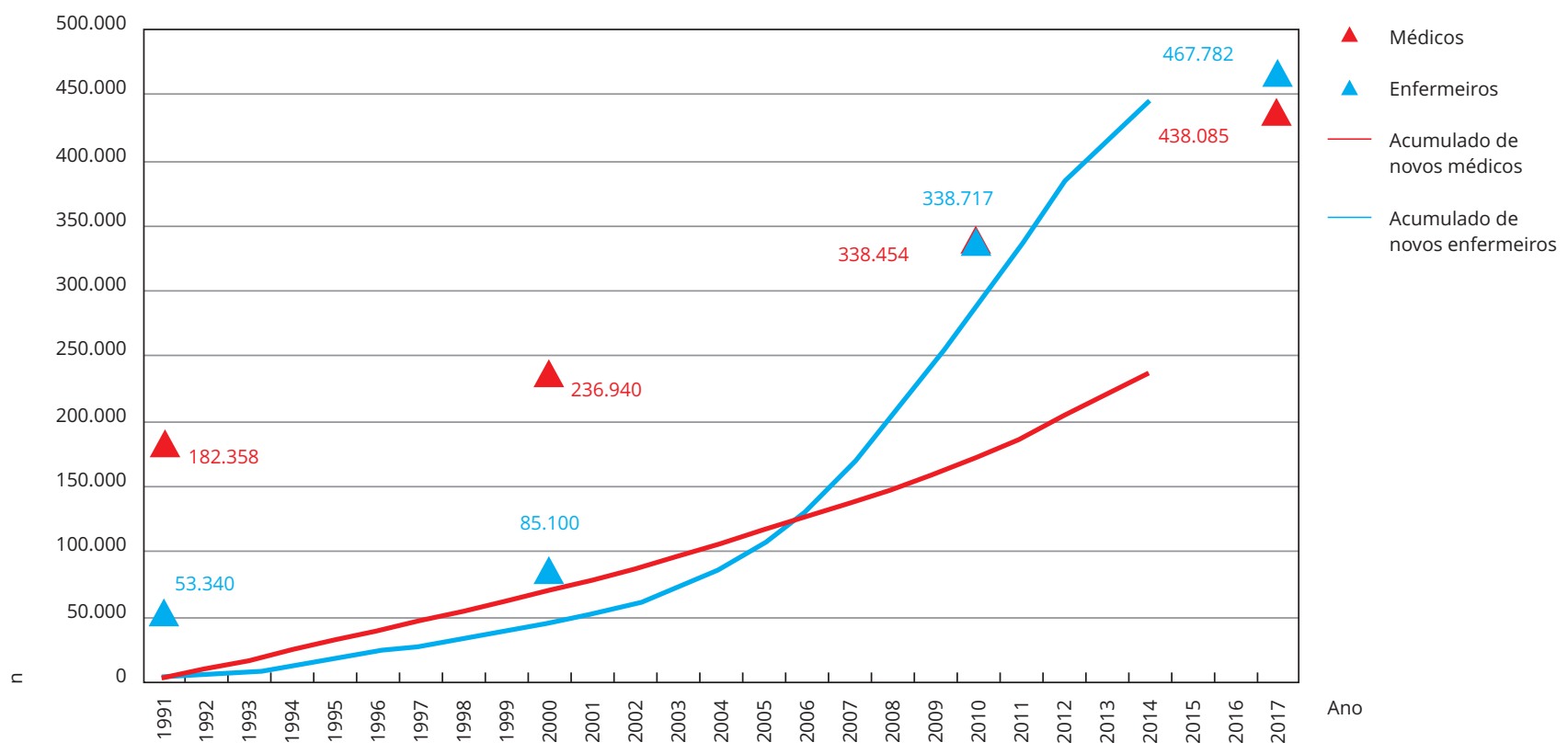

Fonte: elaboração própria a partir de dados do Censo Demográfico do Instituto Brasileiro de Geografia e Estatística (IBGE) de 1991 8, 20007 e 2010 (http://ftp.ibge.gov.br/Censos/Censo_Demografico_2010/Resultados_Gerais_da_Amostra/Microdados/, acessado em 27/Abr/2012), do Censo da Educação Superior do Instituto Nacional de Estudos e Pesquisas Educacionais Anísio Teixeira (INEP) de 1991 a 2014 (http://portal.inep.gov.br/censo-da-educacaosuperior), do Conselho Federal de Medicina (CFM) de 2017 (http://portal.cfm.org.br/index.php?option=com_estatistica, acessado em 24/Mai/2017) e do Conselho Federal de Enfermagem (Cofen) de 2017 (http://www.cofen.gov.br/enfermagem-em-numeros, acessado em 24/Mai/2017). Nota: os números de médicos e enfermeiros em 1991, 2000 e 2010 correspondem ao total de indivíduos residentes no país cujo último curso de formação era de graduação em Enfermagem ou Medicina e ou que estavam ocupados na profissão no trabalho principal da semana de referência do Censo Demográfico, exclusive aqueles com inconsistências nas informações de idade e escolaridade. Os números de 2017 correspondem aos de profissionais com registro ativo nos respectivos conselhos profissionais. O acumulado de novos médicos e enfermeiros representa a soma acumulada dos números de egressos dos cursos de Medicina e Enfermagem, ano a ano, de acordo com o INEP.

variações significativas desse comportamento de 2004 para 2010. Com exceção dos concluintes de 2004, a maioria dos estudantes estava em IES privadas, sendo que a participação deste segmento aumentou em 2010. Houve redução dos respondentes em universidades, comparativamente aos centros universitários e faculdades, mas em todos os grupos de alunos, aqueles ainda representavam a maioria.

O atributo de renda familiar evidencia a principal alteração na base de recrutamento da Medicina. Em 2004, os ingressantes com renda de até 3 salários mínimos (a menor faixa de renda disponível para resposta) perfaziam 9,5\% do total de respondentes, o que passou para 26,6\% em 2010 (Tabela 2). Entre os concluintes, a variação foi de 9,2\% para 23,3\%. De fato, ao longo dos anos 2000 a composição do alunado inverteu, já que em 2004 a maioria tinha renda familiar acima de 10 salários mínimos e, em 2010, a maioria estava abaixo desta faixa. É interessante notar, porém, que essa mudança foi mais significativa em termos econômicos do que sociais, tendo em vista que a composição dos estudantes em termos de escolaridade dos pais e tipo de escola que cursou o Ensino Médio não foi alterada. De maneira geral, permaneceu uma maioria cujos pais possuíam nível superior de escolaridade (em torno de $65 \%$ ) e que haviam cursado o Ensino Médio todo em escola privada (em torno de $80 \%$ ). Note-se ainda que a proporção dos que nunca haviam trabalhado, por ocasião do exame, aumentou. Por fim, 
Tabela 1

Perfil demográfico dos estudantes concluintes e ingressantes, natureza jurídica e forma de organização das Instituições de Ensino Superior (IES) dos cursos de Medicina e Enfermagem. Brasil, 2004 e 2010.

\begin{tabular}{|c|c|c|c|c|c|c|c|c|}
\hline \multirow[t]{3}{*}{ Características } & \multicolumn{4}{|c|}{ Ingressantes (\%) } & \multicolumn{4}{|c|}{ Concluintes (\%) } \\
\hline & \multicolumn{2}{|c|}{ Medicina } & \multicolumn{2}{|c|}{ Enfermagem } & \multicolumn{2}{|c|}{ Medicina } & \multicolumn{2}{|c|}{ Enfermagem } \\
\hline & 2004 & 2010 & 2004 & 2010 & 2004 & 2010 & 2004 & 2010 \\
\hline \multicolumn{9}{|l|}{ Sexo } \\
\hline Masculino & 47,8 & 44,3 & 15,3 & 14,7 & 51,7 & 45,3 & 12,7 & 14,8 \\
\hline Feminino & 52,2 & 55,7 & 84,7 & 85,3 & 48,3 & 54,7 & 87,3 & 85,2 \\
\hline \multicolumn{9}{|l|}{ Faixa etária (anos) } \\
\hline Até 24 & 92,0 & 85,2 & 64,2 & 59,2 & 35,8 & 29,0 & 49,0 & 41,6 \\
\hline $25-29$ & 6,3 & 10,6 & 17,1 & 18,6 & 59,8 & 63,1 & 27,6 & 27,5 \\
\hline $30-34$ & 1,3 & 3,1 & 8,7 & 11,4 & 3,0 & 6,1 & 9,6 & 15,5 \\
\hline $35+$ & 0,4 & 1,2 & 9,9 & 10,8 & 1,3 & 1,8 & 13,8 & 15,4 \\
\hline \multicolumn{9}{|l|}{ Como se considera } \\
\hline Branco(a) & 78,7 & 71,7 & 66,8 & 52,3 & 80,4 & 73,8 & 70,0 & 59,8 \\
\hline Negro(a)/Pardo(a)/Mulato(a) & 17,7 & 25,6 & 30,6 & 45,1 & 15,5 & 23,0 & 27,8 & 38,3 \\
\hline Amarelo(a) & 3,0 & 2,3 & 1,7 & 1,9 & 3,7 & 2,8 & 1,7 & 1,4 \\
\hline Indígena & 0,6 & 0,4 & 0,9 & 0,7 & 0,5 & 0,4 & 0,5 & 0,6 \\
\hline \multicolumn{9}{|l|}{ Estado civil } \\
\hline Solteiro(a) & 98,1 & 95,7 & 77,3 & 76,8 & 93,7 & 93,7 & 74,7 & 70,2 \\
\hline Casado(a) & 1,6 & 3,1 & 16,5 & 16,8 & 4,8 & 4,9 & 18,7 & 22,2 \\
\hline Outro & 0,4 & 1,2 & 6,2 & 6,4 & 1,6 & 1,4 & 6,6 & 7,6 \\
\hline \multicolumn{9}{|l|}{ Com quem mora atualmente } \\
\hline Sozinho(a) & 15,1 & 17,6 & 4,6 & 5,4 & 14,9 & 17,2 & 5,5 & 6,4 \\
\hline Com os pais/parentes & 53,4 & 52,3 & 62,6 & 63,7 & 57,4 & 56,0 & 55,0 & 56,7 \\
\hline Com cônjuge e/ou filho(s) & 1,4 & 3,3 & 19,8 & 21,9 & 5,4 & 5,8 & 22,9 & 27,7 \\
\hline Com amigos ou alojamento & 30,1 & 26,7 & 13,0 & 9,0 & 22,3 & 21,1 & 16,6 & 9,3 \\
\hline \multicolumn{9}{|l|}{ Natureza jurídica da IES } \\
\hline Pública & 47,8 & 38,2 & 16,0 & 16,2 & 51,7 & 43,3 & 31,2 & 13,1 \\
\hline Privada & 52,2 & 61,8 & 84,0 & 83,8 & 48,3 & 56,7 & 68,8 & 86,9 \\
\hline \multicolumn{9}{|l|}{ Forma de organização da IES } \\
\hline Universidade & 72,6 & 64,8 & 53,5 & 39,6 & 76,0 & 69,9 & 63,2 & 39,6 \\
\hline Centro universitário & 6,9 & 10,9 & 17,7 & 16,3 & 3,3 & 7,6 & 17,7 & 22,7 \\
\hline Faculdade & 20,5 & 24,2 & 28,9 & 44,1 & 20,7 & 22,5 & 19,2 & 37,7 \\
\hline
\end{tabular}

Fonte: elaboração própria com base nos microdados do Exame Nacional de Desempenho dos Estudantes (ENADE) de 2004 e 2010 (Instituto Nacional de Estudos e Pesquisas Educacionais Anísio Teixeira - INEP. http://portal.inep.gov.br/basica-levantamentos-acessar, acessado em 03/Out/2016). Nota: amostra de estudantes de Medicina e Enfermagem que responderam ao questionário socioeconômico do ENADE. As categorias das variáveis foram modificadas de maneira a compatibilizar as diferentes versões do questionário em 2004 e 2010. Todas as frequências foram calculadas baseando-se no número de casos válidos.

a proporção dos respondentes que recebiam ou já receberam bolsa ou financiamento para o curso cresceu entre os ingressantes ( $7,7 \%$ para $21,5 \%)$, mas não entre os concluintes.

O perfil da Enfermagem, por sua vez, apresentou um aumento da participação masculina, embora residual e com a sustentação de uma maioria absoluta de mulheres, em torno dos $85 \%$ em todas as categorias de análise (Tabela 1). A composição etária foi mais distribuída do que a da Medicina, com maior presença de pessoas acima dos 30 anos, faixa que passou de $18,6 \%$ para $22,2 \%$, entre ingressantes, e de $23,4 \%$ para $30,9 \%$, entre concluintes. O mesmo pode ser dito sobre a presença de negros(as), pardos(as) ou mulatos(as), que cresceu de 30,6\% para 45,1\%, na entrada da formação, e de $27,8 \%$ para $38,3 \%$, na saída. Em relação à conjugalidade, observaram-se proporções maiores de casados(as) e de estudantes que moravam com o cônjuge e/ou filho(s), relativamente à Medicina. Tais grupos ampliaram 


\section{Tabela 2}

Perfil socioeconômico dos estudantes concluintes e ingressantes dos cursos de Medicina e Enfermagem. Brasil, 2004 e 2010.

\begin{tabular}{|c|c|c|c|c|c|c|c|c|}
\hline \multirow[t]{3}{*}{ Características } & \multicolumn{4}{|c|}{ Ingressantes } & \multicolumn{4}{|c|}{ Concluintes } \\
\hline & \multicolumn{2}{|c|}{ Medicina } & \multicolumn{2}{|c|}{ Enfermagem } & \multicolumn{2}{|c|}{ Medicina } & \multicolumn{2}{|c|}{ Enfermagem } \\
\hline & 2004 & 2010 & 2004 & 2010 & 2004 & 2010 & 2004 & 2010 \\
\hline \multicolumn{9}{|l|}{ Renda familiar (salários mínimos) * } \\
\hline Até 3 & 9,5 & 26,6 & 29,6 & 52,5 & 9,2 & 23,3 & 20,9 & 41,6 \\
\hline $3-10$ & 23,3 & 33,4 & 54,4 & 43,1 & 26,4 & 33,1 & 56,7 & 51,8 \\
\hline $10-30$ & 45,1 & 28,3 & 14,9 & 4,1 & 42,9 & 29,4 & 20,8 & 6,0 \\
\hline+30 & 22,1 & 11,8 & 1,1 & 0,4 & 21,5 & 14,1 & 1,5 & 0,5 \\
\hline \multicolumn{9}{|l|}{ Trabalho durante o curso } \\
\hline Nunca trabalhou & 82,0 & 92,9 & 36,2 & 50,2 & 70,6 & 92,1 & 36,6 & 52,9 \\
\hline Trabalha(ou) eventualmente & 8,0 & 3,7 & 5,3 & 5,1 & 12,4 & 4,5 & 6,7 & 5,0 \\
\hline Trabalha(ou) $<40$ horas semanais & 7,1 & 2,8 & 26,2 & 20,9 & 14,8 & 3,0 & 33,2 & 22,5 \\
\hline Trabalha(ou) $\geq 40$ horas semanais & 2,9 & 0,6 & 32,3 & 23,8 & 2,2 & 0,4 & 23,5 & 19,6 \\
\hline \multicolumn{9}{|c|}{ Recebe(u) bolsa de estudo ou financiamento } \\
\hline Não & 92,3 & 78,5 & 68,7 & 65,6 & 77,4 & 78,6 & 61,4 & 58,0 \\
\hline Sim & 7,7 & 21,5 & 31,3 & 34,4 & 22,6 & 21,4 & 38,6 & 42,0 \\
\hline \multicolumn{9}{|l|}{ Escolaridade do pai } \\
\hline Nenhuma escolaridade & 0,5 & 0,7 & 5,7 & 6,9 & 0,6 & 0,5 & 5,1 & 6,3 \\
\hline Ensino Fundamental (1a a 4a série) & 4,4 & 6,1 & 31,7 & 31,5 & 6,7 & 6,3 & 30,9 & 32,9 \\
\hline Ensino Fundamental (5a a 8a série) & 5,5 & 6,0 & 17,9 & 15,7 & 5,8 & 5,1 & 17,3 & 15,6 \\
\hline Ensino Médio & 22,1 & 27,1 & 29,9 & 33,4 & 18,8 & 21,8 & 29,7 & 31,7 \\
\hline Ensino Superior & 67,5 & 60,1 & 14,8 & 12,4 & 68,2 & 66,3 & 17,0 & 13,5 \\
\hline \multicolumn{9}{|l|}{ Escolaridade da mãe } \\
\hline Nenhuma escolaridade & 0,4 & 0,3 & 5,0 & 5,0 & 0,4 & 0,4 & 4,6 & 5,1 \\
\hline Ensino Fundamental (1 a a 4a série) & 3,1 & 3,4 & 27,4 & 25,7 & 5,0 & 3,5 & 25,9 & 27,1 \\
\hline Ensino Fundamental (5a a 8ạ série) & 4,6 & 4,0 & 16,7 & 14,9 & 5,7 & 4,0 & 16,9 & 14,3 \\
\hline Ensino Médio & 26,3 & 26,2 & 32,0 & 35,1 & 26,8 & 26,3 & 32,3 & 33,5 \\
\hline Ensino Superior & 65,6 & 66,1 & 18,9 & 19,2 & 62,0 & 65,8 & 20,3 & 20,1 \\
\hline \multicolumn{9}{|c|}{ Em que tipo de escola você cursou o Ensino Médio? } \\
\hline Todo em escola pública & 8,3 & 14,7 & 53,1 & 63,4 & 9,4 & 11,5 & 44,9 & 59,1 \\
\hline Todo em escola privada & 81,6 & 77,6 & 27,2 & 23,4 & 77,4 & 79,8 & 35,2 & 26,2 \\
\hline A maior parte em escola pública & 3,5 & 2,6 & 9,2 & 6,0 & 4,8 & 3,3 & 9,2 & 6,9 \\
\hline A maior parte em escola privada & 5,3 & 4,3 & 5,9 & 4,2 & 6,6 & 4,5 & 5,8 & 4,8 \\
\hline Metade pública e metade privada & 1,3 & 0,8 & 4,7 & 2,9 & 1,8 & 0,8 & 4,9 & 3,1 \\
\hline
\end{tabular}

Fonte: elaboração própria com base nos microdados do Exame Nacional de Desempenho dos Estudantes (ENADE) de 2004 e 2010 (Instituto Nacional de Estudos e Pesquisas Educacionais Anísio Teixeira - INEP. http://portal.inep.gov.br/basica-levantamentos-acessar, acessado em 03/Out/2016). Nota: amostra de estudantes de Medicina e Enfermagem que responderam ao questionário socioeconômico do ENADE. As categorias das variáveis foram modificadas de maneira a compatibilizar as diferentes versões do questionário em 2004 e 2010 . Todas as frequências foram calculadas baseando-se no número de casos válidos.

* Intervalos em 2004 = até $R \$ 780,00$; de $R \$ 781,00$ até $R \$ 2.600,00$; de $R \$ 2.601,00$ até $R \$ 7.800,00$; e mais de $R \$ 7.800,00$. Intervalos em $2010=$ até $R \$$ $1.530,00$; de $R \$ 1.531,01$ até $R \$ 5.100,00$; de $R \$ 5.100,01$ até $R \$ 15.300,00$; e mais de $R \$ 15.300,00$.

de forma mais expressiva a sua participação entre os concluintes. No geral, porém, a maioria era de alunos solteiros que moravam com os pais/parentes. A maioria do alunado frequentava seus cursos em IES privadas, as quais representavam mais de 80\% dos ingressantes já em 2004. Os estudantes em universidades diminuíram consideravelmente sua participação, frente ao incremento de estudantes em faculdades.

A renda familiar demonstra que o padrão de recrutamento da Enfermagem derivava fundamentalmente das duas primeiras faixas de renda, isto é, até 3 salários mínimos e mais de 3 até 10, 
intensificadas de 2004 para 2010 (Tabela 2). Apenas na primeira faixa a proporção passou de 29,6\% para 52,5\%, entre os ingressantes, e de 20,9\% para 41,6\%, entre concluintes. Assim como na Medicina, não houve alterações no padrão de escolaridade dos pais. No entanto, na Enfermagem, a proporção de respondentes cujos pais tinham nível superior completo não ultrapassava os $20 \%$, em todos os grupos e períodos. Entre ingressantes e concluintes as proporções com pais sem nível médio completo oscilaram entre 45\% e 50\%. Com esse padrão de origem familiar, de 2004 a 2010 ampliou-se a participação de estudantes que cursaram todo o Ensino Médio em escola pública e que recebiam ou receberam bolsa de estudo ou financiamento. Assim como na Medicina, cresceu a proporção de respondentes que nunca trabalharam, ainda que em níveis menores (de 36,2\% para 50,2\%, entre ingressantes, e de $36,6 \%$ para $52,9 \%$, entre concluintes).

\section{Base social dos habilitados na profissão}

As Tabelas 3 e 4 apresentam aspectos da base social dos habilitados em Medicina e Enfermagem no Brasil, comparativamente ao total da população com nível superior, em 2000 e 2010, de acordo com o Censo Demográfico do IBGE. A primeira tabela corresponde ao total de diplomados nas profissões, independentemente da condição de atividade ou ocupação. Na tabela seguinte selecionam-se apenas os ocupados na própria profissão. Embora a comparação entre os dados do ENADE e do Censo Demográfico não seja direta, é possível interpretar a tendência observada, na década, sobre a base social dos habilitados como um reflexo da ampliação da base social de recrutamento, pelo menos em torno dos atributos de sexo, idade e raça, os quais estão disponíveis nas duas fontes. Assume-se que os profissionais em fase de recrutamento que estavam representados como egressos nos dados de formação necessariamente estavam representados como habilitados na fonte populacional.

Seguindo a feminilização observada entre os estudantes de Medicina, a proporção de médicas cresceu, mas os homens ainda perfaziam a maioria (64,4\%, em 2000, e 57,7\%, em 2010) (Tabela 3). Houve um pequeno rejuvenescimento com o aumento de pessoas com até 29 anos, porém o envelhecimento foi mais expressivo. A proporção de profissionais na faixa etária de 50 a 59 anos aumentou de $16,9 \%$ para $20,7 \%$ e, na faixa de 60 anos e mais, de 11,1\% para 16,5\%. Esse comportamento não está diretamente associado à expansão do Ensino Superior, tendo em vista que o padrão etário na formação não foi alterado. A composição segundo raça ou cor da pele ainda não acompanhou a maior entrada de negros no Ensino Superior. O que se observou foi um crescimento residual de pardos, de $9,2 \%$ para $12,7 \%$. A proporção de pretos permaneceu em torno de $1 \%$. No que se refere à posição do entrevistado em relação ao responsável pelo domicílio amostrado, diminuiu a proporção de responsáveis, aumentando as demais, sobretudo a de cônjuge ou companheiro(a).

A população ocupada na profissão representava 78,9\% da força de trabalho médica em 2000, o que aumentou para 84,7\% em 2010. Foi significativa a redução de ocupados em funções que não exigem nível superior (de 8,1\% para 3\%). Os ocupados em outra profissão de nível superior, os desocupados e os não economicamente ativos mantiveram-se no mesmo patamar, em torno de $2,5 \%, 1 \%$ e $8 \%$, respectivamente (Tabela 3). Entre os ocupados na profissão, ocorreu um aumento do assalariamento, isto é, de ocupados como estatutários ou celetistas, e redução dos empregadores (Tabela 4). Os ocupados em trabalhos com menos de 39 horas semanais diminuíram a sua participação frente aos ocupados com carga horária entre 40 e 44 horas. Dentre os empregados sem carteira, conta própria e empregadores, diminuiu a proporção dos que contribuíam para a Previdência, de 83,9\% para 78,4\%. Aumentou residualmente o número de médicos ocupados que estavam aposentados, de 9,9\% para 11,8\%. Quanto ao rendimento mensal do trabalho, em 2000, 97,8\% dos médicos estavam localizados no $10^{\circ}$ decil da distribuição de renda do total da população ocupada no país. Em 2010, eram 85,3\%. Com essa redução aumentou a quantidade localizada nos demais níveis da distribuição, sobretudo no 9o decil. Se considerarmos o rendimento domiciliar per capita, porém, a maioria permaneceu localizada no $10^{\circ}$ decil, com uma pequena perda em relação ao $9^{\circ}$ decil.

A composição da força de trabalho em Enfermagem refletiu o aumento da participação de homens nos cursos de graduação, já que o número de enfermeiros variou de 8,6\% para 13,5\% (Tabela 3). O rejuvenescimento foi sentido de forma significativa com o incremento do número de profissionais com até 29 anos de idade, que passou de 19,9\% para 36,2\%. Todas as demais faixas etárias perderam participação relativa na composição populacional. Diferentemente da Medicina, o aumento de negros 
Tabela 3

Distribuição dos médicos e enfermeiros e do total da população com nível superior, segundo atributos demográficos. Brasil, 2000 e 2010.

\begin{tabular}{|c|c|c|c|c|c|c|}
\hline \multirow[t]{2}{*}{ Características } & \multicolumn{2}{|c|}{ Médicos } & \multicolumn{2}{|c|}{ Enfermeiros } & \multicolumn{2}{|c|}{ População com nível superior } \\
\hline & 2000 & 2010 & 2000 & 2010 & 2000 & 2010 \\
\hline \multicolumn{7}{|l|}{ Sexo } \\
\hline Masculino & 64,4 & 57,7 & 8,6 & 13,5 & 45,8 & 41,9 \\
\hline Feminino & 35,6 & 42,3 & 91,4 & 86,5 & 54,2 & 58,1 \\
\hline \multicolumn{7}{|l|}{ Faixa etária (anos) } \\
\hline Até 29 & 14,2 & 15,8 & 19,9 & 36,2 & 17,4 & 23,3 \\
\hline $30-39$ & 28,4 & 26,1 & 34,6 & 30,8 & 31,0 & 28,7 \\
\hline $40-49$ & 29,4 & 21,0 & 26,3 & 17,6 & 27,8 & 22,0 \\
\hline $50-59$ & 16,9 & 20,7 & 10,1 & 9,8 & 15,0 & 15,5 \\
\hline 60 e mais & 11,1 & 16,5 & 9,2 & 5,7 & 8,7 & 10,6 \\
\hline \multicolumn{7}{|l|}{ Raça/Cor da pele } \\
\hline Branca & 86,2 & 83,2 & 72,7 & 65,1 & 82,5 & 73,4 \\
\hline Preta & 1,1 & 1,3 & 4,5 & 6,0 & 2,2 & 3,8 \\
\hline Amarela & 2,9 & 2,7 & 2,7 & 1,5 & 2,3 & 2,0 \\
\hline Parda & 9,2 & 12,7 & 19,4 & 27,3 & 12,5 & 20,8 \\
\hline Indígena & 0,2 & 0,1 & 0,2 & 0,1 & 0,1 & 0,1 \\
\hline Ignorado & 0,4 & 0,0 & 0,4 & 0,0 & 0,4 & 0,0 \\
\hline \multicolumn{7}{|l|}{ Posição no domicílio } \\
\hline Responsável pelo domicílio & 65,8 & 57,7 & 35,2 & 34,1 & 49,8 & 45,3 \\
\hline Cônjuge ou companheiro(a) & 19,7 & 24,7 & 41,8 & 30,8 & 29,0 & 28,4 \\
\hline Filho(a)/Enteado(a) & 11,5 & 12,1 & 16,6 & 26,1 & 17,4 & 20,3 \\
\hline Outro parente & 2,5 & 4,1 & 5,6 & 7,2 & 3,6 & 5,0 \\
\hline Outra posição & 0,4 & 1,3 & 0,8 & 1,7 & 0,3 & 1,0 \\
\hline \multicolumn{7}{|l|}{ Condição de atividade } \\
\hline Ocupado na profissão & 78,9 & 84,7 & 56,8 & 48,9 & 46,7 & 41,5 \\
\hline Ocupado em outra profissão de nível superior & 2,8 & 2,1 & 1,8 & 3,2 & 5,9 & 9,8 \\
\hline Ocupado em função que não exige nível superior & 8,8 & 4,2 & 21,6 & 28,4 & 27,8 & 30,2 \\
\hline Desocupado & 1,4 & 0,6 & 3,1 & 5,6 & 4,0 & 2,7 \\
\hline Não economicamente ativo & 8,0 & 8,4 & 16,7 & 13,9 & 15,6 & 15,8 \\
\hline
\end{tabular}

Fonte: elaboração própria baseando-se nos Censos Demográficos de 20007 e de 2010 (http://ftp.ibge.gov.br/Censos/Censo_Demografico_2010/ Resultados_Gerais_da_Amostra/Microdados/, acessado em 27/Abr/2012).

Nota: amostra de indivíduos com nível superior completo, exclusive aqueles com inconsistências nas informações de idade e escolaridade. Os médicos e enfermeiros eram aqueles que haviam concluído curso de Medicina ou Enfermagem e/ou que estavam ocupados na própria profissão no trabalho principal da semana de referência. Todas as frequências foram calculadas com base no número de casos válidos e utilizando-se o peso analítico 24.

foi mais intenso, até porque o acesso deste grupo ao Ensino Superior foi maior na Enfermagem. É interessante notar, porém, que o aumento foi mais importante entre os que se declaravam pardos (19,4\%, em 2000, e 27,3\%, em 2010), comparativamente aos pretos (4,5\% e 6\%). O número relativo de responsáveis pelo domicílio permaneceu em torno de $35 \%$, o de cônjuges diminuiu de 41,8\% para $30,8 \%$ e do de filhos(as) aumentou de $16,6 \%$ para $26,1 \%$, o que pode ser explicado pelo rejuvenescimento da força de trabalho.

Os enfermeiros se ocupavam na própria profissão em patamares muito inferiores aos que se observaram entre os médicos. Em 2000, eram 56,8\% e, em 2010, 48,9\%. Note-se que essa redução foi acompanhada do aumento de ocupados em funções que não exigem nível superior, de desocupados e de ocupados em outras profissões de nível superior. Também reduziu os não economicamente ativos (Tabela 3). Entre os ocupados na profissão não se assistiu a alterações na estrutura ocupacional, tendo em vista que se manteve uma maioria ocupada como celetista, em torno de 62\%, seguida de estatutários, em torno de 25\% (Tabela 4). Assim como ocorreu entre os médicos, aumentou a proporção de 
Tabela 4

Distribuição dos médicos, enfermeiros e população com nível superior ocupada na própria profissão, segundo aspectos do trabalho principal da semana de referência e rendimentos. Brasil, 2000 e 2010.

\begin{tabular}{|c|c|c|c|c|c|c|}
\hline \multirow[t]{2}{*}{ Características } & \multicolumn{2}{|c|}{ Médicos } & \multicolumn{2}{|c|}{ Enfermeiros } & \multicolumn{2}{|c|}{ População com nível superior } \\
\hline & 2000 & 2010 & 2000 & 2010 & 2000 & 2010 \\
\hline \multicolumn{7}{|l|}{ Posição na ocupação } \\
\hline Empregado celetista & 33,2 & 37,5 & 63,4 & 62,0 & 42,3 & 44,7 \\
\hline Estatutário & 14,3 & 19,0 & 25,3 & 25,0 & 18,7 & 23,6 \\
\hline Empregado sem carteira & 11,7 & 10,3 & 8,4 & 9,9 & 8,1 & 8,7 \\
\hline Conta própria & 28,9 & 27,1 & 2,6 & 2,4 & 19,8 & 18,3 \\
\hline Empregador & 11,3 & 6,0 & 0,2 & 0,3 & 10,6 & 4,6 \\
\hline Não remunerado & 0,6 & 0,1 & 0,1 & 0,2 & 0,5 & 0,2 \\
\hline \multicolumn{7}{|c|}{ Horas que habitualmente trabalhava por semana } \\
\hline Até 20 & 18,5 & 15,0 & 5,1 & 7,3 & 13,8 & 16,0 \\
\hline $21-39$ & 24,2 & 16,4 & 36,7 & 25,1 & 19,0 & 16,5 \\
\hline $40-44$ & 26,1 & 35,9 & 42,9 & 51,2 & 45,3 & 52,6 \\
\hline Acima de 44 horas & 31,0 & 32,7 & 15,3 & 16,5 & 22,0 & 14,9 \\
\hline \multicolumn{7}{|c|}{ Se contribuía para Previdência * } \\
\hline Sim & 83,9 & 78,4 & 61,0 & 55,8 & 66,3 & 61,1 \\
\hline Não & 16,1 & 21,6 & 39,0 & 44,2 & 33,7 & 38,9 \\
\hline \multicolumn{7}{|l|}{ Se estava aposentado } \\
\hline $\operatorname{Sim}$ & 9,9 & 11,8 & 3,9 & 4,3 & 8,7 & 7,5 \\
\hline Não & 90,1 & 88,2 & 96,1 & 95,7 & 91,3 & 92,5 \\
\hline \multicolumn{7}{|c|}{ Decis do rendimento mensal do trabalho ** } \\
\hline Até a mediana & 0,1 & 1,2 & 0,2 & 5,7 & 0,7 & 8,0 \\
\hline 6 으 e 7으 & 0,1 & 1,6 & 0,3 & 10,3 & 1,2 & 12,7 \\
\hline 8으 & 0,3 & 2,5 & 1,2 & 15,9 & 2,5 & 15,6 \\
\hline 9o & 1,8 & 9,4 & 7,7 & 33,7 & 11,5 & 22,6 \\
\hline 10으 & 97,8 & 85,3 & 90,6 & 34,4 & 84,1 & 41,2 \\
\hline \multicolumn{7}{|c|}{ Decis do rendimento domiciliar per capita *** } \\
\hline Até a mediana & 0,1 & 0,3 & 0,5 & 2,5 & 0,5 & 3,7 \\
\hline $6 \underline{0}$ e $7 \underline{0}$ & 0,2 & 0,6 & 1,4 & 6,5 & 2,1 & 7,4 \\
\hline 80 & 0,5 & 1,0 & 3,5 & 10,1 & 4,2 & 9,3 \\
\hline 9oㅡ & 2,9 & 4,5 & 17,3 & 24,0 & 14,6 & 20,6 \\
\hline 10 으 & 96,3 & 93,6 & 77,3 & 56,9 & 78,6 & 59,0 \\
\hline
\end{tabular}

Fonte: elaboração própria baseando-se nos Censos Demográficos de 20007 e de 2010 (http://ftp.ibge.gov.br/Censos/Censo_Demografico_2010/ Resultados_Gerais_da_Amostra/Microdados/, acessado em 27/Abr/2012).

Nota: amostra de indivíduos com nível superior completo, ocupados na própria profissão, exclusive aqueles com inconsistências nas informações de idade e escolaridade. Os médicos e enfermeiros eram aqueles ocupados na própria profissão no trabalho principal da semana de referência. Todas as frequências foram calculadas com base no número de casos válidos e utilizando-se o peso analítico 24.

* Aplica-se apenas aos ocupados nas posições de empregado sem carteira, conta própria, empregador e não remunerado, já que estatutários e celetistas possuem regime compulsório de contribuição previdenciária;

** Decis calculados com base na distribuição de renda do total da população ocupada no país;

*** Decis calculados com base na distribuição da renda per capita do total de domicílios no país.

trabalhadores com carga horária entre 40 e 44 horas e os que não contribuíam para a Previdência. A proporção de ocupados que estavam aposentados permaneceu em torno de 4\%. Já a distribuição de renda sofreu uma intensa transformação, tendo em vista que os profissionais que se localizavam no 10 o decil da distribuição de renda passaram de $90,6 \%$ para $34,4 \%$ do total. Com isso, passaram a se localizar gradativamente nos decis anteriores. De forma menos intensa, mas ainda substantiva, o mesmo ocorreu para o rendimento domiciliar per capita. 


\section{Discussão e conclusão}

As profissões de nível superior passaram por um amplo processo de expansão no Brasil como resultado das políticas públicas para o ensino superior, iniciadas desde a segunda metade da década de 1990. De um lado, cita-se a Lei de Diretrizes e Bases da Educação Nacional de 1996 que impulsionou os processos de diferenciação institucional, diversificação curricular e desburocratização do sistema de ensino 9. Por outro, as políticas de democratização do acesso, como as cotas sociais e raciais, e as de financiamento ou permanência dos estudantes, como o Programa de Financiamento Estudantil (FIES), de 1999, e o Programa Universidade para Todos (PROUNI), de 2004, entre outros 10. Esse cenário expansionista resultou em um aumento da população de titulados com nível superior no país de 6,1 milhões, em 2000 7, para 13,4 milhões, em 2010 (incremento de 14,1\% ao ano) (IBGE. http:// ftp.ibge.gov.br/Censos/Censo_Demografico_2010/Resultados_Gerais_da_Amostra/Microdados/, acessado em 27/Abr/2012).

Note-se que Medicina e Enfermagem ampliaram a sua oferta em níveis muito distintos de 2000 para 2010. Enquanto o incremento de médicos foi de 3,6\% ao ano, o de enfermeiros acompanhou a tendência do conjunto das profissões do país a $14,8 \%$ ao ano. A resposta do mercado de trabalho em saúde do ponto de vista da disponibilidade de postos de trabalho demonstrou situações de escassez dos primeiros 11 e sobreoferta dos segundos 12 . O mercado médico se mostrou mais dinâmico em termos de empregabilidade e melhoria nos níveis salariais, já o mercado da Enfermagem vivenciou (e ainda vivencia) alto nível de desemprego e demanda por empregos muito abaixo da oferta, embora tenha crescido consideravelmente no período ${ }^{13}$. De fato, situações tão distintas conviveram com um mesmo cenário de maiores e mais complexas demandas por serviços de saúde relacionadas, entre outros fatores, ao envelhecimento populacional, incremento tecnológico, avanço das políticas públicas de saúde e da população portadora de planos de saúde, e diversificação das atividades biomédicas 13,14.

Nesse cenário dos anos 2000, como os dados aqui analisados sugerem, os grupos profissionais da Medicina e Enfermagem ampliaram sua base social de recrutamento e recompuseram sua base social de habilitados. Esse processo ocorreu de forma distinta ao compararmos as duas profissões, destacando-se a existência de diferenças na capacidade de cada grupo em mobilizar recursos que são próprios do mundo profissional e que lhes podem garantir posições especiais no mercado de trabalho e na estrutura social. Embora apresentados de forma descritiva, os dados suscitam um interessante debate sobre os efeitos da expansão do Ensino Superior brasileiro para as desigualdades no mundo profissional.

A Medicina representa um grupo profissional em que a principal fonte de recrutamento deriva de estratos sociais de alta renda, compostos de indivíduos cujos pais possuem alta escolaridade, que têm oportunidades de cursar o Ensino Médio em escolas privadas e que se declaram da cor branca. Esse perfil reduziu sua importância nos anos 2000 pelo recrutamento expressivo de jovens em estratos de renda mais baixa e, em menor medida, que se declararam negros. O perfil de estratos de alta renda, porém, permaneceu majoritário. É interessante notar que a nova base social de recrutamento é diferente quanto ao capital econômico, mas não quanto ao capital social, pois também é composta de indivíduos com pais altamente escolarizados, que cursam o Ensino Médio em escolas privadas e que predominantemente se declaram brancos.

A Enfermagem, por sua vez, inverteu sua base social de recrutamento, de um perfil derivado de estratos sociais de renda intermediária a alta para um perfil de renda baixa. De maneira geral, isso implicou intensificação da participação de indivíduos que já eram expressivamente representados na profissão, aqueles com idades acima do padrão previsto para cursar o Ensino Superior, casados, que se declararam negros e que cursaram o Ensino Médio em escola pública. Também não foi alterada a composição desse grupo no que se refere ao capital social, apesar da alteração no capital econômico. Aqui, porém, predomina o contingente de estudantes com pais sem o Ensino Médio completo, mas com importante representação no Ensino Superior. A despeito da ampliação do recrutamento em estratos de baixa renda, aumentou a proporção de estudantes que não trabalharam durante o curso, $o$ que pode ser explicado pela importância conferida por eles à formação de nível superior como estratégia de mobilidade social.

As duas profissões, porém, não podem ser vistas isoladamente. Ao menos desde a década de 1960 quando o Ensino Superior brasileiro como um todo vem passando por democratização no acesso, 
sobretudo com maior entrada de mulheres, pretos, pardos e indígenas. Entretanto, esse processo não se deu igualmente, produzindo uma forte estratificação horizontal, isto é, a existência de hierarquias entre carreiras universitárias. Nesse sentido, a ampliação da base social do ensino superior tem acontecido desigualmente em direção a profissões que são consideradas menos valorizadas pelo mercado de trabalho e pela sociedade como um todo, justamente aquelas preferidas pelas IES privadas devido ao baixo custo de abertura e manutenção dos cursos 15. De fato, a expansão do ensino superior amplamente apoiada no setor privado e em carreiras desvalorizadas tem sido fonte de produção de desigualdades entre profissões, já que os futuros profissionais passam a ser selecionados na entrada do ensino superior segundo atributos de origem familiar 9 .

A Enfermagem pode ser localizada no centro desse padrão de expansão. Ao lado de carreiras como Geografia, História, Pedagogia, Fisioterapia, Administração, entre outras, apresentou um perfil dependente do setor privado, com altos níveis de desperdício de vagas e abandono dos cursos e que recebe um alunado, em sua maioria, proveniente de estratos sociais de baixa renda em busca de ascensão social. Já a Medicina pode ser localizada junto à Arquitetura, Engenharias e Direito, perfazendo um perfil próximo de universidades públicas, com altos níveis de aproveitamento das vagas e eficiência terminal da formação e que atraem estudantes de origem em estratos sociais de alta renda em busca de carreiras prestigiadas 15,16,17.

É importante ressaltar que essa diferenciação entre profissões expressa chances distintas de sucesso profissional. De fato, desde os anos de 1980 foram ampliadas as restrições de acesso qualificado no mercado de trabalho brasileiro como um todo, o que resultou em aumento do desemprego nos anos iniciais das trajetórias laborais e o aumento da competição pelas posições no mercado 18 . O impacto desse contexto para as trajetórias de inserção na estrutura social foi o da diminuição dos retornos educacionais 19. Mesmo com a ampliação do acesso ao Ensino Superior no país, a escolarização deixou de ser garantia de mobilidade social, ainda que ela permaneça como meio de reprodução social. Há evidências que mostram que a quantidade de anos de estudos aumentam as chances de mobilidade ascendente. Porém, independentemente desta associação, a classe social de origem continua sendo o principal determinante dos percursos pessoais em direção à classe de destino. A educação atua como um meio importante de mobilidade social ascendente, mas, sobretudo de reprodução de estratos sociais de alta renda 20.

A reprodução das classes de alta renda, portanto, ficou menos evidente com a expansão e democratização do Ensino Superior após 1996, porém, isto é menos verdadeiro para as profissões que controlam áreas sociais mais prestigiadas, como é o caso da Medicina. Assim, um dos fatores que explicam a diminuição da vantagem de renda entre pessoas com nível superior é a expressiva disparidade de rendimentos entre as diferentes carreiras 21, como é o caso das profissões aqui analisadas. Outro fator é o elevado grau de incompatibilidade entre ocupação e educação. Assim, quanto menos os diplomados se ocupam na própria profissão, menores são as chances de auferirem altos rendimentos 21 , o que também ficou evidenciado neste estudo. No cômputo geral, o avanço educacional na sociedade brasileira parece ter sido relevante para reduzir desigualdades, mas não para alterar substantivamente a estrutura de classes 22 , e a seletividade de origem social no recrutamento das diferentes profissões, mesmo com a ampliação da sua base social, destaca a rigidez desta estrutura.

Nesse sentido, Medicina e Enfermagem representam situações opostas que contribuem para esse processo de reprodução social. Pelo lado da Medicina, observa-se que seu mercado de trabalho segue fundado em práticas autônomas de inserção laboral e, sobretudo de maiores possibilidades de exercer a profissão em diferentes cenários clínicos e administrativos na área da saúde, o que contribui para perfazer altos rendimentos e altas proporções de diplomados exercendo a profissão 13,23. A Enfermagem, por sua vez, é uma das profissões da área da saúde com maiores dificuldades de inserção no mercado de trabalho, o que se deve, entre outros fatores, por ser uma categoria cuja inserção laboral depende de uma trajetória típica (assalariada), majoritariamente a partir de um único vínculo de trabalho e com rendimentos mais baixos, implicando altas concentrações de desemprego, abandono da profissão e desajuste ocupacional (exercício de outras funções que não a própria profissão) 12,13.

Este trabalho contribuiu para mostrar descritivamente como os percursos da Medicina e da Enfermagem ao longo do processo de expansão do Ensino Superior, iniciado no final dos anos 1990, nos contam sobre as desigualdades sociais no mundo profissional contemporâneo. Em trabalhos futuros poderão ser abordadas perguntas como: de que maneira as profissões negociam sua identidade 
diante da sociedade quando sua base social é ampliada? As trajetórias de mobilidade social por meio da profissionalização vividas por indivíduos de classes baixas permitem superar desigualdades de origem? Como os títulos acadêmicos são negociados socialmente para a superação dessas desigualdades, sobretudo em termos de gênero, raça e classe social?

\section{Agradecimentos}

À Capes pela bolsa de doutoramento. À professora Luciana Andrade e demais colegas da disciplina de Elaboração de Artigos Científicos do PPGCS da PUC-Minas pelos comentários. À EPSM/NESCON/UFMG pelo acesso aos dados processados do Censo Demográfico e do Censo da Educação Superior.

\section{Referências}

1. Brint S. Profesiones y mercado. Rev Esp Invest Sociol 1992; 59:161-203.

2. Barbosa MLO. O ensino superior no Brasil: credencial, mérito e os coronéis. In: Barbosa MLO, organizador. Ensino superior: expansão e democratização. Rio de Janeiro: 7 Letras; 2014. p. 51-69.

3. Weeden KA. Why do some occupations pay more than others? Social closure and earnings inequality in the United States. Am J Sociol 2002; 108:55-101.

4. Barbosa MLO. Para onde vai a classe média: um novo profissionalismo no Brasil? Tempo Social 1998; 10:129-42.

5. Diniz M. Neomarxistas e Neoweberianos: sobre a natureza do estrato profissional. Dados 1996; 39:101-37. 
6. Chaves M, Morais C. Nivelação e desigualdade na inserção profissional de diplomados do ensino superior. Sociologia, Problemas e Práticas 2014; 76:87-108.

7. Instituto Brasileiro de Geografia e Estatística. Microdados do Censo Demográfico: amostra de uso público [CD-ROM]. Rio de Janeiro: Instituto Brasileiro de Geografia e Estatística; 2000.

8. Instituto Brasileiro de Geografia e Estatística. Microdados do Censo Demográfico: amostra de uso público [CD-ROM]. Rio de Janeiro: Instituto Brasileiro de Geografia e Estatística; 1991.

9. Prates AAP, Collares ACM. Desigualdade e expansão do ensino superior na sociedade contemporânea: o caso brasileiro do final do século XX ao princípio do século XXI. Belo Horizonte: Fino Traço; 2014.

10. Barbosa MLO. Destinos, escolhas e a democratização do ensino superior. Política e Sociedade 2015 ; 14:256-82.

11. Girardi SN, Carvalho CL, Araújo JF, Wan Der Maas L, organizadores. Mercado de trabalho médico: escassez e desigualdades na distribuição da força de trabalho no Brasil. Belo Horizonte: Estação de Pesquisa de Sinais de Mercado, Núcleo de Educação em Saúde Coletiva, Faculdade de Medicina, Universidade Federal de Minas Gerais; 2013.

12. Machado MH, Oliveira E, Lemos W, Lacerda WF, Aguiar Filho W, Wermelinger M, et al. Mercado de trabalho em enfermagem: aspectos gerais. Enferm Foco 2016; 7:35-62.

13. Estação de Pesquisa de Sinais de Mercado. Estudo de levantamento de aspectos demográficos, de formação e de mercado de trabalho das profissões de saúde de nível superior no Brasil entre 1991 e 2010. Relatório de pesquisa. Belo Horizonte: Estação de Pesquisa de Sinais de Mercado, Núcleo de Educação em Saúde Coletiva, Faculdade de Medicina, Universidade Federal de Minas Gerais; 2014.

14. Dal Poz MR, Pierantoni CR, Girardi S. Formação, mercado de trabalho e regulação da força de trabalho em saúde no Brasil. In: Fundação Oswaldo Cruz, organizador. A saúde no Brasil em 2030: prospecção estratégica do sistema de saúde brasileiro. v. 3: organização e gestão do sistema de saúde. Rio de Janeiro: Fundação Oswaldo Cruz/Instituto de Pesquisa Econômica Aplicada/Ministério da Saúde/Secretaria de Assuntos Estratégicos da Presidência da República; 2013. p. 185-235.
15. Ribeiro CAC, Schlegel R. Estratificação horizontal da educação superior no Brasil (1960 a 2010). In: Arretche M, organizadora. Trajetórias das desigualdades: como o Brasil mudou nos últimos cinquenta anos. São Paulo: Editora Unesp; 2015. p. 133-62.

16. Coradini OL. Mercado escolar, de trabalho e usos da titulação universitária. Repocs 2015; 12:115-32.

17. Barbosa MLO, Santos CT. A permeabilidade social das carreiras do ensino superior. Caderno CRH 2011; 24:535-54.

18. Cardoso A. A construção da sociedade do trabalho no Brasil: uma investigação sobre a persistência secular das desigualdades. Rio de Janeiro: Editora FGV; 2010.

19. Santos JAF. Mudanças de renda no Brasil: fatores espaciais, setoriais, educacionais e de status social. Sociedade e Estado 2015; 30:749-72.

20. Ribeiro CAC. Mobilidade e estrutura de classes no Brasil contemporâneo. Sociologias 2014; 16:178-217.

21. Reis MC, Machado DC. Uma análise dos rendimentos do trabalho entre indivíduos com ensino superior no Brasil. Brasília: Instituto de Pesquisa Econômica Aplicada; 2015. (Texto para Discussão, 2110).

22. Souza PHGF, Carvalhaes FAO. Estrutura de classes, educação e queda da desigualdade de renda (2002-2011). Dados 2014; 57:101-28.

23. Scheffer M, Biancarelli A, Cassenote A. Demografia médica no Brasil 2015. São Paulo: Departamento de Medicina Preventiva, Faculdade de Medicina, Universidade de São Paulo/Conselho Regional de Medicina do Estado de São Paulo/Conselho Federal de Medicina; 2015.

24. Barbosa RJ. Instruções para o uso de bancos de microdados das amostras dos censos demográficos brasileiros (1960 a 2010). Rio de Janeiro: Centro de Estudos da Metrópole; 2013. (Nota Técnica). 


\section{Abstract}

The aim of this study was to analyze the changes in the 2000s in the social base of the medical and nursing professions in Brazil, as a result of the expansion of higher education in the country beginning in the late 1990s. The article begins with a descriptive analysis of the social base of recruitment, drawing on data from the socioeconomic questionnaire of the National Student Performance Exam in 2004 and 2010, for incoming and graduating students in medicine and nursing. Next, it analyzes the social base of certified physicians and nurses, using data from the 2000 and 2010 Population Censuses. The results show that there was an expansion in the social base of recruitment in both professions, especially an increase in students from low-income families and those self-identified as black or brown. The social base of certified physicians and nurses underwent a reconfiguration, characterized by rejuvenation and a decrease in work market remuneration. The two processes were experienced differently within and between the professions, highlighting the existence of differences in the respective professional groups' capacity to mobilize resources proper to the professional world and that can guarantee special positions in the work market and in social structure.

Health Occupations; Allied Health Occupations; Higher Education; Medicine; Nursing

\section{Resumen}

El objetivo de este artículo es analizar las alteraciones ocurridas durante la primera década del año 2000, en lo que se refiere a la base social en las profesiones de medicina y enfermería en Brasil, como resultado de la expansión de la enseñanza superior, iniciada en la segunda mitad de la década de 1990. Por un lado, se analiza descriptivamente la base social en la selección de personal, valiéndose de los datos de la encuesta socioeconómica del Examen Nacional de Desempeño de los Estudiantes, desde 2004 hasta 2010, en cuanto a quienes accedian y concluían los cursos de medicina y enfermería. Por otro, se analiza la base social de los habilitados en esas profesiones, usando los datos del Censo Demográfico de 2000 y 2010. Los resultados muestran que se produjo una ampliación de la base social en el acceso a estas dos profesiones, sobre todo por el crecimiento del alumnado proveniente de familias de baja renta, $y$ que se declararon negros/as, mestizo/as y mulato/ as. Ya la base social de quienes fueron habilitados sufrió una reconfiguración, caracterizada por el rejuvenecimiento de la población, y por la disminución de los subsidios en el mercado de trabajo. Ambos procesos fueron vividos de forma distinta entre y dentro de las propias profesiones, destacando la existencia de diferencias en la capacidad de cada grupo profesional al movilizar recursos, que son propios del mundo profesional, y que les pueden garantizar posiciones especiales en el mercado de trabajo y en la estructura social.

Empleos en Salud; Empleos Relacionados con Salud; Educación Superior; Medicina; Enfermería

Recebido em 07/Out/2016

Versão final reapresentada em 19/Jun/2017

Aprovado em 05/Jul/2017 